\title{
Adapting an In-person Transdiagnostic Social Skills Program to Online Delivery: Technology to the Rescue
}

\author{
Bruce M. Gale",a, Shayna Greenberg ${ }^{b}$, Katrina Ireland ${ }^{\circ}$
}

\author{
Received \\ Revised \\ Accepted \\ DOI
}

\author{
23 July 2020 \\ 7 November 2020 \\ 8 January 2021 \\ 10.26822/iejee.2021.199
}

Correspondance Details: Bruce M. Gale, BehaviorTech Solutions, Inc., California, USA. E-mail: bgale@behaviortech.net

ORCID: https://orcid.org/0000-0003-0855-8431

bShayna Greenberg,

BehaviorTech Solutions, Inc., California, USA.

E-mail: sgreenberg@bgalephd.com

ORCID: https://orcid.org/0000-0002-7525-6268

\section{'Katrina Ireland,}

BehaviorTech Solutions, Inc., California, USA. E-mail: katrina@bgalephd.com

ORCID: https://orcid.org/0000-0002-0416-6396

\begin{abstract}
Social skills intervention programs have demonstrated treatment efficacy in session but putting that knowledge into practice is a critically important component. It requires simultaneous development of related essential skills, like emotion regulation and resilience. Additionally, transdiagnostic treatment methodologies, which are more cost-effective and increase accessibility, have become increasingly popular. However, accessibility remains a problem for in-person programs. LUNCH Groups ${ }^{\circledR}$ (wwW. lunchgroups.com), an in-person transdiagnostic program, incorporated various technology-based assessment and intervention elements as part of the original program design. These included a customized online assessment tool, home generalization app, computer animation projects, and online parent webinars. Their inclusion paved the way for a quick pivot to telehealth-based services while maintaining HIPAA compliance. The original in-person program is described along with the steps taken in the switch to telehealth, outlining the benefits and challenges that resulted. Attendance and attrition data indicated no problems after an initial adjustment period that coincided with the onset of the pandemic. Survey data indicated general satisfaction with the revised program structure and curriculum, with significant gains approximating those seen in the in-person version.
\end{abstract}

\section{Keywords: \\ Social Skills, Telehealth, Pandemic, Transdiagnostic, \\ Group Treatment}

\section{Introduction}

Children and adolescents who experience behavioral and social difficulties often face social isolation as their peers form group dynamics that are difficult for them to understand (Schohl et al., 2014). Social skills programs can help children put together a toolbox of abilities for social competence such as effective use of verbal and nonverbal communication, appropriate timing, appropriate topics, and planning situation-specific responses (Spence, 2003). While skill knowledge is helpful, putting that knowledge into practice is a critically important component (Bandura, 1977; Gates et al., 2017; Schohl et al., 2014; Spence, 2003). The transition from practicing and competently applying social 


\section{iejee $\approx$}

skills in controlled, structured environments to more dynamically changing, less predictable, naturalistic contexts can be challenging. It is critical to help individuals simultaneously develop related essential skills like emotion regulation, resilience, attentiveness, and awareness of self and their environment (Gale et al., 2017; Spence, 2003)

Social skills treatment spans a broad spectrum. Of the most commonly used interventions, notable differences include the level of structure (ranging from primarily instruction-focused to peer-mediated group games) and the element of parental training (Gates et al., 2017). A strong example of a replicated evidence-based social skills intervention method has been demonstrated in multiple programs (e.g., PEERS ${ }^{\circledR}$ Program, Summer Treatment Program (STP)). These implemented high structure and also supplemented sessions with parent training (Fabiano et al., 2014; Schohl et al., 2014). Additionally, transdiagnostic treatment methodologies, which are more cost-effective and increase accessibility (Barlow \& Farchione, 2017), have become increasingly popular with school-aged youth due to rapidly changing developmental profiles and comorbidity (Chu et al., 2016). It has also been found to be effective with social skills treatment (FernándezMartínez et al., 2020; Gale, 2011). While transdiagnostic treatment strategies have been shown to be effective for supporting youth, accessibility to in-person interventions is limited.

The vast majority of research on online social skills interventions has focused on asynchronous methods, including specially designed online games, instructional modules, and video modeling clips (Soares et al., 2020). Interest in the use of virtual reality to simulate social learning has also become more common recently (Didehbani et al., 2016; Kandalaft et al., 2013). The translation of in-person social skills groups into an online, synchronous setting, however, has received very limited attention.

Prior to the COVID-19 pandemic, synchronous online therapy, or teletherapy, has been embraced for its accessibility as a valuable alternative to faceto-face treatment (Goldstein \& Glueck, 2016). In addition to assessing the feasibility of logistical matters of technology, privacy, and standardization, researchers have examined effectiveness through attendance and attrition data, as well as qualitative information such as satisfaction, connectedness, and engagement (Davies et al., 2020; Weinberg, 2020). At home, a client may feel more comfortable, safe, and willing to be vulnerable. However, it can be prone to far more distractions than a clinician's office, with pets, family members, or toys taking away from the client's ability to focus (Goldstein \& Glueck, 2016). It also affects nonverbal cues prompting inadvertent interruptions (Payne et al., 2020).
In a recent survey from June 2020, 128 allied health providers who provided behavioral, speech, and social skills interventions to nearly 27,000 individuals with autism and related developmental disabilities were surveyed. Looking specifically at online group treatment programs, $34.5 \%$ found it to be more effective than in-person in some or all areas, $17.2 \%$ found it to be equally effective, $27.6 \%$ found mixed effectiveness, $13.8 \%$ found it less effective but still a viable alternative, and $7 \%$ found it to be much less effective (Gale, 2020). In looking forward, $92.4 \%$ of these vendors reported planning to create hybrid service delivery models that combined online and in-person.

Online telehealth is still a relatively new modality for running any type of group treatment. Insufficient research exists to demonstrate its effectiveness fully, and clear guidelines are lacking (Weinberg, 2020). With the COVID-19 pandemic outbreak, traditional in-person services ground to a sudden halt, leaving clinicians to rely upon their best clinical judgment to develop and implement variations of existing treatment and novel treatments.

\section{Development of LUNCH Groups ${ }^{\circledR}$ : A Transdiagnostic Social Learning Program}

The LUNCH Groups ${ }^{\circledast}$ social learning program, now in its 19th year, began almost by accident. The first author had been consulting at a public school when a fifth grader, who had been bullied and teased, drew a picture. The student who had been bullied drew the picture only after repeated episodes of the alleged bully, a classmate, tripping him, knocking possessions off his desk, and flicking him in the head while passing by, all undetected by the teacher and other staff. Feeling alone and ignored, the bullied student drew three objects on a piece of paper: a boy's face, a gun, and a grave with flowers. He did not show it to anyone, but the teacher caught sight of it.

While such drawings should never be dismissed or minimized, this student was simply expressing his anger ineffectively and inappropriately. He had no means to obtain a weapon (his planning skills were a major area of weakness) and he was highly impulsive - quick to anger and equally quick to forget what upset him in the first place. This did not stop the school staff, however, from informing the parents of the bullied student that their son's drawing would result in automatic expulsion, even though the United States' Individual with Disabilities Education Act (IDEA) required a manifest determination hearing in such cases (U.S. Dept of Education, 2001)

The family elected to fight the decision. Fourteen hours of Individual Education Program (IEP) meetings ensued, with the outcome being that the first author was contracted by the school district to design and 
implement a social skills program to teach this student and other targeted peers about anger control, empathy, and peer interaction skills. Ultimately, the district desired this student and others to develop an understanding of the consequences of making threats or engaging in other serious behaviors. Ironically, the student who had engaged in bullying was not required to participate.

What began as a lunchtime meeting serving eight fourth and fifth graders, involving a data projector, portable screen, and laptop for creating computer animation stories and other projects, evolved into two ongoing practice-based, time-limited programs for ages six to 18, split across four age groups (lower elementary, upper elementary, middle school, and high school). To date, over 1600 families have participated in the LUNCH Groups ${ }^{\circledast}$ Social Skills Program.

\section{Core Treatment Targets}

Helping individuals achieve a sense of selfefficacy, develop resilience, and become proficient using positive coping behaviors are essential for mastery of social skills. Key components of social skills interventions require real-life settings where individuals need to expend varying degrees of effort to practice and sustain strategies in the face of obstacles and subjectively threatening (but ultimately safe) experiences (Bandura, 1977). To this end, the program has created carefully constructed group experiences in office and community settings, with parents providing opportunities to further develop and practice these skills at home. On rare occasions (not frequently enough), it has been possible to introduce our strategies into the child's school environment, either through individual teacher consultation or a school-wide inservice for educational staff.

While some earlier researchers noted challenges in generalization after successfully teaching essential skills as part of a group training procedure (Berler et al., 1982); other researchers have reported more success with generalization (Laugeson et al., 2012). LUNCH Groups $^{\circledast}$ (www.lunchgroups.com) incorporates various technologies to enhance motivation in targeting traditional social skills involving executive functioning, pragmatic language, social competence, academic readiness, daily living skills, and environmental awareness (Gale, 2011) (see Table 1 below). In addition to addressing traditional social skills, the $\mathrm{LUNCH}$ Groups $^{\oplus}$ also addresses externalized behaviors (i.e., disruptive, socially unacceptable, and uncooperative behaviors) and internalizing behaviors (i.e., anxiety, worrying, sadness, perception-based, and fear-based symptoms)

The program came upon its name thanks to the effort of those inaugural student participants. "LUNCH" became an acronym for Learning, Understanding, Negotiating, Communicating, and Helping. The acronym acts as a global mission statement to convey the main tenets of the program. For example, students are reminded that any animation or other creative project shared in the group, has to include one of these primary concepts, and this has been effective in guiding participants to create stories that deliver meaningful messages void of violence or aggression.

\section{Table 1}

Primary Treatment Targets

Executive Function $\quad$ Pragmatic Language Social Competence

Paying attention Planning/Organization Self-monitoring Self-regulation (emotional control) Effective judgment Working memory Successful coping strategies Accepting feedback
Using and reading non-verbal facial and gestural cues

Looking at situations from the perspective of others Knowing when (and how) to "jump in" to a discussion Adjusting language usage to fit the audience
Maintaining effective conversations Knowing how to act in common social situations

Giving brief and concise responses Remaining on topic

Modulating voice level for different situations

\section{Daily Living}

Academic Readiness

Environmental Awareness

Basic nutritional understanding Understanding the importance of sufficient sleep

Maintaining hygiene-related behaviors Trying new foods

Global Restaurant behavior

Responsible technology use
Remaining seated in class Written and oral comprehension Participating in group activities Focusing on the immediate task or conversation

Effective hand-raising

Recognizing what is appropriate conversation and social boundaries for school
Pedestrian safety

Effective behavior in community settings, such as restaurants, stores, malls, parks, and community events Knowing what is safe vs dangerous in the community and taking appropriate cautions 


\section{iejee}

\section{Global Program Components}

Many details need to be considered in developing a viable program. Below are some of the primary program areas of the LUNCH Groups ${ }^{\oplus}$, with a discussion of how program elements may be (and have been) modified to an online delivery format.

\section{Transdiagnostic Approach}

Early on, LUNCH Groups ${ }^{\circledR}$ incorporated elements of both school and day camp using a transdiagnostic approach. This meant that the LUNCH Groups ${ }^{\circledast}$ treatment approach could be applied to students with a variety of challenges. The majority of students had executive function and pragmatic skill deficits, learning challenges, or anxiety problems without significant interfering behaviors. A smaller number of students, generally less than 15\%, presented with oppositional defiant disorder (ODD), meaning they would persistently argue, appear irritable, refuse requests, or act in a vindictive manner. Our research discovered that as long as the percentage of students presenting with ODD remained relatively low, the involvement of students with ODD in the program did not significantly impact the program quality. Placing disruptive behaviors on extinction, while rewarding any degree of cooperation of the student, has been a successful strategy for working with students with ODD. Furthermore, students who present with ODD symptomatology have benefited from instructional control gained via behavioral momentum techniques.

Some LUNCH Groups ${ }^{\circledast}$ student participants have presented with both internalizing and externalizing characteristics. Once students who present as oppositional reduce or cease their maladaptive behavior, they often demonstrate an underlying lack of self-confidence, experience performance anxiety, and speak negatively about themselves. It has been important to protect these students who initially might have presented as disruptive and defiant as well, since their initial belligerence might have been off-putting to peers and/or misinterpreted by peers and staff. Many students with ODD lack the skills necessary to address their internalizing feelings once their antisocial behavior is better controlled. It has been our researchers' experience that problems with oppositional behavior manifested in groups rarely continues beyond a couple of sessions.

Children who exhibit extreme shyness, even selective mutism, have also participated in LUNCH Groups ${ }^{\circledR}$, with their numbers limited to less than $15 \%$ of the group. Such children are typically able to speak at home with no problem but refuse to speak at school or in other public settings. As with oppositional children, children with extreme shyness or selective mutism have been rewarded for extremely small approximations of speaking behavior, such as a head nod. This provides a feeling of safety while exposing them to numerous participant modeling opportunities, ensuring that they are not asked to actively participate at levels they find unmanageable.

There have been many benefits to opening the LUNCH Groups $^{\oplus}$ program to students who present with a wide range of behavioral challenges and characteristics. Because they are all dealing with different challenges, students also present with a wide variety of strengths. For example, an advanced student may act as a model for demonstrating reading comprehension or critical thinking skills, but they typically may need to work on not constantly raising their hand or critiquing others. A good-natured but inattentive student may model turn-taking and complimenting peers, while a shy student may appear alert, and yet, actually be attentive. In other words, the program plays one child's skills off another's. Students learn to develop tolerance for others' differences through perspective-taking and empathy development. These can be protective factors for reducing bullying (Horne et al. 2012; Trip et al., 2015). The drawback is that if the group is not properly balanced, more time is needed on behavior management aspects.

Internalizing students focus more on their own thoughts and feelings, which can be difficult for others to observe, e.g., anxiety or shyness. Asocial students have little desire for social interaction. Both of these groups experience group interactions quite differently than those who engage in more prominent externalizing symptoms. This is especially important during the first few sessions. The trajectory for improvement varies depending upon these students' characteristics. For students with more internalizing characteristics, it is important to recognize the mere experience of being around new students can be anxiety-provoking. Taking steps to ensure the group environment is perceived as a safe setting is paramount.

Group sizes have varied significantly over sessions. For the elementary school groups, there can be up to 12 and for the older groups, up to 18 participants. Ethnicity ranges from program to program, based upon referrals.

\section{Pivoting to Online}

Very few changes have occurred in the transdiagnostic method of participant selection. Previously, assessment occurred to screen for potential harm to peers, especially with students with more severe levels of attention deficit hyperactivity disorder (ADHD), autism spectrum disorder (ASD), and ODD. A standing treatment exclusion has been requiring zero levels of physical aggression during the previous six months. Fortunately, no peer has been physically 
injured due to the behavior of another peer. Since there is no physical contact in online treatment, this screening step became irrelevant, and students have been successfully accepted online where there might have been more reservations based upon prior history.

The groups have reduced in size since moving to online, with a maximum of eight attendees for the elementary school programs and up to 12 students for the middle and high school groups.

\section{Initial Assesment}

In developing the assessment methods for LUNCH Groups ${ }^{\circledR}$, a primary goal has been to determine the necessary essential information to identify target behaviors and measure progress. The assessment process was designed to balance the informationgathering process while making it as comfortable as possible for the child potentially entering treatment. There are three discrete steps: parent interview, behavior survey, and child interview. These identify adaptive prosocial behaviors to be increased and the frequency and severity of specific interfering behaviors to be decreased. In meeting with the student, the goal was to better understand their level of language expression and comprehension, plus their level of pragmatic understanding. As a result, the following process emerged:

\section{Step 1: Parent phone consultation}

Family members are scheduled for an initial telephone interview, typically lasting about 30 minutes but occasionally lasting up to an hour. Parents typically ask questions about the program during this time. This portion of our process has remained unchanged during our pivot to online intervention. A semistructured approach is used to gather information about the child's school situation, which helps to target relevant academic skills. Other areas include social relationships, hobbies, outside activities, sibling relationships, sleep, independence, eating habits, and medical information.

This also begins the parent education component about their expected role in the process, advocating an authoritative parenting style as opposed to authoritarian or permissive (Lavrič \& Naterer, 2020; Steinberg et al., 1992). This occurs in greater detail during the subsequent parent orientation.

The final portion of the parent interview asks them to identify the most important areas to address. Most parents will make a global statement about wanting their child to "behave better" or "socialize more." If necessary, information from the interview and the results of Rapid Screener ${ }^{\oplus}$ are used to help them identify more easily observable behaviors. Below are some samples from prior assessments:
- "... to improve in his tele-learning skills, to be willing to sit and be engaged, to help him learn to manage distractions, as well as managing his negative emotions more effectively." (Age 7)

- "... to be more accepting of others' ideas and to be more aware of times when she is acting in a more strident manner with peers. Helping her to have more balanced and reciprocal interactions, recognize and control when she is interrupting others, and pay attention are additional goals." (Age 9)

- "... to expand to new and different textures in foods, have better table manners, say "hello" and "goodbye" (she has never done this), and reduce her self-stimulatory behavior." (Age 13)

- "... to interact more appropriately with his peers. Goals also include increasing his level of independence regarding his hygiene." (Age 17)

\section{Step 2: Online assessment}

Families complete an online social-emotional assessment of their child's behavior using Rapid Screener ${ }^{\oplus}$, a HIPAA-compliant single or multi-rater wide-band tool (Gale, 2011). It was designed to complement other common social skills assessment tools, such as the Behavior Assessment Scale for Children (BASC), Child Behavior Checklist ( $\mathrm{CBCL})$, and Social Skills Intervention System (SSIS) (Anthony et al., 2020; Cui et al., 2004; Papazoglou et al., 2013). It is composed of six adaptive clusters that mirror those described earlier and the five interfering behavior clusters cover a similarly broad range, including symptoms consistent with oppositional defiant disorder, conduct disorder, autistic spectrum, anxiety spectrum, depression, thought disorders, and trauma. Previous research indicated that Rapid Screener ${ }^{\circledR}$ results compare favorably to the SSIS (Harrell \& Gale, 2014). One unique feature of this tool is that it permits raters to report how much behavior change/progress has been observed over a specific period of time. The typical completion time is 15 minutes, although some raters complete it in as little as eight minutes.

\section{Step 3: Student interview}

One of the greatest challenges has been how to usefully assess a student while not turning them off to the idea of participating in our program. During the in-person meeting portion of the assessment, how the parent and child enter the physical interview room can be most telling. Some children come in sullen, rude, silent, or ignoring the assessor. The parents had previously been informed the meeting is "95\% for their child".

The child is initially asked what they know about our program. These answers are typically revealing. Sometimes they will respond that they had no idea they were coming for an appointment, which creates an opportunity to commend them for being so flexible. Other times, they say they have come for a "social skills 


\section{iejee}

program." This permits further inquiry and explanation since they rarely understand what that means. A therapy dog has been part of the program since two years after its inception. The animal is kept in another room as the student was asked if they wanted to meet it while explaining the animal was very friendly and liked kids. This is typically a positive element, but occasionally it elicits dog fears. In the past five years, only one child declined to meet the therapy dog, and this decision was respected despite the parent trying to persuade them into doing otherwise.

The parent and child transition into the larger meeting room, equipped with a large movie screen and data projector. Depending upon the child's age and functioning, they will be shown either an animation and/or video snippets from previous LUNCH Groups ${ }^{\circledast}$ sessions.

\section{Using Animation to Assess Pragmatic Understanding}

The length of the animation is limited to those that are three minutes or less. Watching how the child attends, reacts, and responds subsequently can provide valuable information. By using animations with no dialogue, it becomes a purer measure of nonverbal understanding without the confound of oral language comprehension.

\section{Using Video to Evaluate Social Understanding}

Children typically view a 12-minute video depicting various events from previous programs (Groups between 2007 to 2012). This provides both samples of how the group operates and provides opportunities for the child to indicate their understanding of various scenes. Some of the areas covered include understanding relationships and examples of participant modeling (Bandura et al., 1975). The latter is an essential treatment component that is integrated with the use of social beacons. Other aspects of the video include seeing positive practice where a student repeats a behavior to gain mastery and fluidity. All of these methods have translated to an online approach without difficulty.

\section{Teenage Consent to Participate}

There are special rules when a student is 16 and older in that they are directly asked if they want to participate. As long as they do not actively refuse, they are accepted for treatment. Since implementing this policy, only a few adolescents have adamantly refused to participate.

\section{Pivoting to Online}

With the exception of moving from in-person student interviews to an online format, the process has remained nearly identical. It is now possible to complete assessments in a few days since scheduling and transportation barriers are reduced or eliminated. Once the initial assessment is completed, parents participate in a live webinar or recorded webinar to ensure they are exposed to our basic principles of applied behavior analysis and social cognition theory, with an emphasis on developing learning skills.

\section{Time-Limited Treatment}

Having a fixed time period and cost has facilitated receipt of referrals through school districts and the Department of Developmental Services (DDS). It has also proven more affordable to families. Fees are set by the DDS and families pay a separate materials fee for raffle prizes and guest presenters. Lower income families are accommodated.

The school year program runs for eight months, from October through May, with after-school student meetings held twice monthly (see Table 2). Holding meetings for 90 minutes has resulted in reduced attrition and increased overall attendance. Additionally, it provided a more suitable period for practicing essential skills.

During the schoolyear, in-office parent meetings were held monthly prior to the pandemic. Parents reviewed videos of their children and discussed the strategies presented to them by the trainers. Additionally, a monthly online webinar covered behavior basics, the implementation of authoritative parental strategies, and related areas. These meetings were conducted "radio show" style, in which parents are encouraged to ask questions about their children. They could speak online or use the chat function; in which case their question or situation was presented anonymously. The groups' customary in-person schedule is depicted below in table 2 .

\section{Table 2}

School-Year Program Treatment Schedule

\begin{tabular}{lll}
\hline & Lower/Upper Elementary School & Middle/High School \\
Start Time & 4 PM & 4 PM \\
Session Length & 2 hours & 2.5 hours \\
Frequency & Twice monthly & Twice Monthly \\
Meal type & Shopping/Snack at start of session & Restaurant meal second half of \\
Live Parent Meetings & Monthly (90-120 minutes) in office & session \\
Parent Webinars & Monthly, 1 hour & Monthly (90-120 minutes) in office \\
& & Monthly, 1 hour \\
\hline
\end{tabular}


Table 3

In-Person Summer Program Treatment Schedule

\begin{tabular}{lll}
\hline & Upper Elementary/Middle School & High School \\
\cline { 2 - 3 } Start Time & 9 AM & 9 AM \\
Session Length & 7 hours & 7 hours \\
Frequency & 10 sessions (MWF) & Morning/Afternoon snacks, lunch \\
Meal type & Morning/Afternoon snacks, lunch & Weekly, 1 hour, weekend meetings \\
Parent Meetings & Weekly, 1 hour, weekend meetings & Weekly, 1 hour (telemeeting) \\
Parent Webinars & Weekly, 1 hour (telemeeting) & \\
\hline
\end{tabular}

In addition to the typical school-year treatment program, the LUNCH Groups ${ }^{\circledast}$ offers a summer alternative as well (see Table 3). The summer program approximates a typical camp session period, with both indoor and outdoor activities, plus field trips to the zoo, museums, bowling, and other recreational activities.

Separate parent meetings are held for the elementary level groups and for middle/high school groups. An extra meeting is available for all groups combined. Parent participation is considered mandatory. Families who do not attend are contacted to encourage participation. The program is run by the first author and previously additional master's and doctoral level staff have also run the program. Paraprofessional staff receive initial training prior to assisting plus ongoing supervision and case conferencing.

\section{Pivoting to Online}

On March 10, 2020, the last in-person program was run, with several absences. One week later, the online version of the four programs was launched, retaining approximately $90 \%$ of families. For the school year program, the format was changed to weekly meetings, and this model has been maintained for 2020-2021. During in-person sessions, natural breaks are built into the program, i.e., walking, transitioning to and from snacks, etc. For the online version, students are provided seven-minute breaks half-way through for the 60-minute meetings and seven to ten-minute breaks two-thirds of the way through the 75-minute programs. Monthly parent meetings have continued, however, strictly online.

For the summer 2020 program, the program was condensed to six 90-minute sessions. Parent participants later reported that they desired the summer program to have lasted longer and included more sessions. Our researchers are revising the program for this coming summer to meet the parents' needs.

The future plan is to offer a hybrid program, where those students who can safely participate in an inperson program will do so with proper precautions. Students who participate via telemeeting will be able to participate for an hour of the office-based portion of the program.

\section{Membership Status}

Group members are either categorized as "New" or "Alumni," the latter reserved for those who have continued or returned from the previous session. Approximately $60 \%$ of members are returning Alumni. There is no maximum number of times a participant can attend, but most families participate for two to four courses of the program. Alumni members are called upon to explain the group rules and provide related information about raffles and other activities to new members during the introductory session. They may be given additional responsibilities, including leading selected activities. There is no formal reassessment for continuing students unless they have not participated in the program in more than one year. In that case, the online assessment tool is readministered to gather baseline data, and parents are briefly interviewed to learn about major life changes.

\section{Pivoting to Online}

No change in any procedures regarding the use of membership designation occurred during the switch to online treatment.

\section{Reinforcement Procedures}

LUNCH Groups ${ }^{\circledast}$ uses a variety of reinforcement procedures, which include raffles, social beacons, and LUNCH Points ${ }^{\mathrm{TM}}$. Prior to raffles being held, students

\section{Table 4}

Online Program Treatment Schedule

\begin{tabular}{lll}
\hline & Lower/Upper Elementary School & Lower/Upper Elementary School \\
Start Time & $3: 30 \mathrm{PM}$ & $3: 30$ PM \\
Session Length & 1 hour & 1 hour \\
Frequency & Weekly & Weekly \\
Meal type & Encouraged to have snack & Encouraged to have snack \\
Live Parent Meetings & Monthly 60 minute telemeetings & Monthly 60 minute telemeetings \\
Parent Webinars & Scheduled for final 3 months & Scheduled for final 3 months \\
\hline
\end{tabular}




\section{iejee}

earn blue tickets for commonly expected behaviors, such as remaining attentive for sustained periods and raising their hand without calling out. During outings, students are rewarded with raffle tickets for effective listening, staying on topic, vocal intonation, and showing interest. Since it occurs in public, points are tallied on a sheet instead of physically awarding tickets. Hero tickets are reserved for important behaviors that occur less frequently, such as peer consideration, emotional regulation, and distress tolerance.

Students who already perform at high levels act as social beacons. They are sometimes rewarded in order to gain the attention of their peers, inducing them to model that behavior. Rewards may also be given to peers who notice and comment on what they observed (e.g., "Did Rick just get a ticket because he's paying attention?"). Newer participants and those with more internalizing characteristics are placed on a denser reinforcement schedule. Invariably, other students will make a positive statement upon observing this (e.g., "Wow, they never give out that many)," which enhances the rewarding event's potency. Variations occur, such as giving initial larger rewards to oppositional students for appropriate modeling or using group contingencies.

LUNCH Points ${ }^{\text {TM }}$ is an online app developed to help parents effectively reinforce any of approximately 70 prosocial behaviors tied to Rapid Screener ${ }^{\circledR}$, an online social-emotional assessment tool, to promote home generalization. Target behaviors include homework completion, hygiene, getting to bed on time, getting along with siblings, effective decision-making, and tolerating minor distress, plus levels of independence and behavioral fluidity are rated. Parents are encouraged to give the LUNCH Points ${ }^{\mathrm{TM}}$ Certificate at least a few days prior to the next session.

In a school year program, there are typically three raffle sessions spaced out at two and a half month intervals. Each consists of a blue ticket and hero ticket raffle, held separately. During initial sessions, students in the group discuss what kinds of prizes they wish to win. On the day of the raffle, the students' tickets are drawn. The winner goes to the adjoining room and selects their prize. Positive behavior is modeled, practiced, and reinforced even when the students retrieve a prize. Students who show more symptoms of generalized anxiety disorder (GAD) or general indecisiveness may be given a time extension, letting them know they can return after the next student has taken their turn if necessary.

\section{Pivoting to Online}

Several changes occurred in the move to online. It has been helpful to shape and reward students for positioning themselves properly online. Increasing both the number of raffles and the frequency of presenter presentations has also facilitated interest (e.g., animal expert, children's author, comedian, music composer).

Raffles are now held approximately once every six weeks, down from ten weeks. Instead of tickets, the students' names are tracked on a spreadsheet and are copied onto a digital roulette wheel. The prize levels are divided into three slightly different amounts, and the prize totals are combined into a single gift card value. After all of the students have been awarded their prize money, they shop online, the link is captured and sent to their parents along with the gift card. Parents receive instruction on how to interact with their children to make it a productive experience.

The use of social beacons has been modified. While tickets could quietly be awarded via the chat function, others would not see it unless the chat feature was made public (kept off due to previous problems). Typically, tickets are announced to the group, though individual chat messages are sent when it is determined the student might be embarrassed by having their positive behavior acknowledged publicly (especially true in the early phases with internalizing students).

Novel methods for increasing student motivation are currently being piloted. For example, after a student with previous oppositional behavior reported that he had improved in reducing homework completion time while also maintaining emotional control for his "positive share of the week" activity, an award certificate was named after him. The other students were informed that they could also opt to commit to working on challenging behavior. Several students have chosen to target specific challenging behaviors since that time. Group leaders intentionally do not inform the parents of the specific challenging behavior that the child has chosen to target for improvement. Instead, the parents receive an email one day prior to the subsequently scheduled group, asking if they have noted any behavioral changes within their child. If the parents detect a positive behavioral change corresponding with the student's targeted behavioral change, then the group participant receives an additional acknowledgement in the form of a unique certificate during group. During the four sessions in which this practice has been in effect, nearly all the students committed to changing specific behaviors. Over one-third of parents' independent reports matched with their child's improved targeted behavior.

\section{Session Curriculum}

The school year and summer programs have a clear structure. However, within that, the program is very much dynamically driven. Engaging in large and small- 
group activities (e.g., computer animation projects, games, and eating out) has resulted in a naturalistic environment that uniquely targeted each child's skills deficits. Quickly switching activities, letting students take over a leadership role, and splitting up into smaller groups then returning as one large group have been effective strategies for improving executive function skills. Students are routinely rewarded for spontaneous participation, consideration toward peers, inoffensive humor, self-regulation, and behavioral fluidity.

The eating aspect had been a major component. For the elementary school age groups, working on shopping skills, awareness of others, effective communication in public, regrouping to eat together, and trying new foods have been primary targets for skill development. For the middle and high school groups, trying novel restaurants, behaving politely in a restaurant, pacing while eating, and hygienically sharing items (e.g., appetizers, splitting meals) are some of the related life skills addressed.

In both programs, the naturalistic and comforting environment associated with consuming food serves as a petri dish for growing and developing conversational skills.

\section{Pivoting to Online}

The loss of being able to shop for and consume snacks and go out to eat together has been a significant change to the program, and many alumni students have stated they miss this activity. Students are encouraged to have snacks during online meeting time, but it just is not the same. The focus has narrowed to enhancing tele-social and tele-learning skills while devising other means to promote generalization. The creation of online games to promote leadership and social interaction has helped to take the place of social activities previously derived from sharing meals together in-person

\section{Using Computer Animation}

The process of creating PowerPoints, animations, and strip comics has been compelling and flexible. Aligned with research on parent praise for effort rather than outcome (Gunderson et al., 2013), there is a greater focus on the process of creating a project as opposed to trying to make it perfect. Some students are selected for more prominent roles (i.e., speaking parts), while others may select a specific character, create dialogue, choose music, pick a specific background or theme, or act in a myriad of other ways to participate effectively. Examples include joke-telling projects, creating and narrating original stories, and making group holiday cards.

\section{Pivoting to Online}

The use of computer animation during sessions has changed very little between in-person and online program formats, although projects take longer than they did in the office. More importantly, during in-person, students would often engage in short, quiet conversations with nearby peers while some technical aspect occurred, such as resizing a graphic or rendering an effect. Helping them practice keeping their voices down and returning their attention to the group task appeared to help with self-monitoring and conversational skills. This has not been possible online. Students were initially permitted to use the "chat feature" built into telemeeting software, but this resulted in more inattention and one-sided, disjointed chat exchanges. As tele sessions have progressed, students appear to be taking more of an interest in one another's lives. Most sessions begin with students relaying a positive event from the previous week, and it has been impressive observing this practice evolve with an accompanying sense of camaraderie and prolonged spontaneous interaction.

\section{Parent Intervention}

Parent support and education have multiple components. These include live in-person, or recorded orientation webinars to help parents understand the program's theoretical orientation (a blend of applied behavior analysis, social cognitive theory, and cognitive-behavioral theory), ways to support their child, and specific strategies to use (and avoid). The kinds of behaviors covered in the program are discussed. Additionally, how sessions operate, safety and emergency procedures, and specific intervention strategies, are reviewed. An importantelement involves how to drop off and pick up their child. This seemingly simple activity often is the genesis for problems. Examples that interfere with program participation include arguing on the way to group, threatening a child with a negative consequence to occur after group because of a school report, promising the child a treat for attending group, and telling them to "try it," while informing them a parent will be nearby if they do not like it.

During in-person sessions, parents review snippets of recent group videos. Additionally, webinars were held covering many of the procedures and techniques used in the group. These include teaching techniques such as instructional control, behavioral momentum, contingency management, differential reinforcement, prompting and modeling, and cognitive-behavioral interventions designed to help their children use more effective problem-solving strategies. Parents also use email consultation 


\section{iejee}

\section{Pivoting to Online}

The parent support component has been one of the easiest and most successful changes. Previously, parents would sign up for office meetings, canceling at the last minute due to transportation, childcare problems, and other unexpected events. Now that parent meetings are solely online, attendance at parent meetings has tripled. Additionally, while video snippets either had to be compiled or shown in an unedited format, now there is a single continuous video recorded for each session.

\section{Managing the Administrative Process}

Fortunately, much of the existing procedures occurred in an online environment before the pandemic. The HIPAA-compliant version of Formsite.com is used to create and manage intake forms, treatment agreements, release forms, Rapid Screener ${ }^{\circledR}$ data, and feedback surveys. Reports are created and stored in the HIPAA-compliant version of Google. Outcome data is posted on the program website.

Below are some of the amendments made to the Office Policies and Agreement for LUNCH Groups ${ }^{\oplus}$ in the move to online services. These were designed to improve client confidentiality and safety, facilitate increased attention, reduce distractions, address emergency situations, and provide a means for managing technological challenges:

- I will not permit photographing or recording of the on-screen images of any of the participants.

- Another responsible adult or I will be on site but not in the immediate vicinity during the time my child participates in the Telehealth session (except briefly to solve technical problems).

- I will provide my child with a quiet space that is free of distractions during the time they participate in the Telehealth meeting.

- I agree to be responsible if my child or I experience a crisis or medical situation during the course of the Telehealth meeting.

- I will let LUNCH Groups ${ }^{\circledR}$ staff know if I encounter problems using the technology.

\section{Program Analysis}

\section{Attrition}

Attendance to group sessions was reviewed as an objective measure of program feasibility, clinical utility, and engagement. Analyses were primarily conducted using archived data originally collected for internal program evaluation purposes and to engage group participants and their families in the clinical process. As such, raw quantitative and qualitative data collection were not standardized across programs. Similarly, the duration and number of sessions ranged across programs. All attendance data were standardized by calculating and comparing the proportion of sessions attended.

Group attendance was analyzed to compare the potential impact of moving from in-person to online. Between July 2019 and December 2020, we compared the attendance percentage across our summer and school year programs during five different time periods (see Fig 1 below). Due to the brief but intensive nature of the summer programs (2019-in-person; 2020-Online), attendance to all sessions was calculated. Conversely, a three-month period was assessed for each of the school year programs (2019-2020-in-person; 2019-2020-Online; 2020-2021-Online). Doing so kept the number of sessions and time duration per sample relatively balanced.

A total sample of 178 data points was collected across all five programs. Students were able to participate in multiple programs if they were determined to be clinically appropriate for continued services. In the Summer 2019 in-person program, there were zero early terminations, and this was maintained for our Summer 2020 online program. Six students, 12\%, dropped out during the in-person 2019-2020 program, higher than usual. Reasons for drop out included severity of problem behaviors, transportation issues, scheduling conflicts, and loss of interest. In transitioning to online, an additional four students did not continue. Once the online program was underway, with 38 unique students, three students terminated early due to preference for in-person services. Since then, no families have terminated early (through December 2020).

\section{Figure 1}

Timeline of LUNCH Groups ${ }^{\oplus}$ Programs from June 2019 to January 2020 and Number of Students Analyzed, Per Group

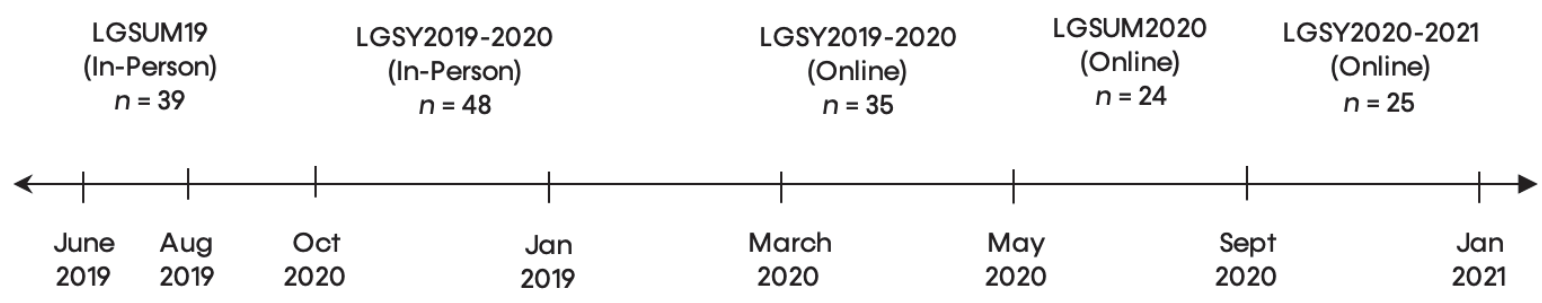


Table 5

Summary of Rates of Attrition for Students Across LUNCH Groups ${ }^{\circledR}$ Programs

\begin{tabular}{|c|c|c|c|c|c|}
\hline \multirow{2}{*}{ Program } & \multirow{2}{*}{ Platform } & \multirow{2}{*}{$\frac{\text { Baseline }}{n}$} & \multirow{2}{*}{$\frac{\text { Terminated }}{n}$} & \multicolumn{2}{|c|}{ Completed } \\
\hline & & & & $n$ & $\%$ \\
\hline Summer 2019 & In-Person & 39 & 0 & 39 & 100 \\
\hline School Year 2019-2020 & In-Person & 52 & 6 & 46 & 88 \\
\hline School Year 2019-2020 & Online & 38 & 3 & 35 & 92 \\
\hline Summer 2020 & Online & 24 & 0 & 24 & 100 \\
\hline School Year 2020-2021 & Online & 25 & 0 & 25 & 100 \\
\hline
\end{tabular}

Reviewing rates of attrition across programs suggests zero attrition during both intensive summer programs, regardless of the environment (In-Person and Online). At the three-month mark, attrition rates were similarly consistent with the Online LUNCH Groups ${ }^{\circledR} 2020-2021$ program. Conversely, greater attrition rates were observed during the in-person and online $\mathrm{LUNCH}$ Groups $^{\oplus}$ 2019-2020 School Year Program, with 88\% and $92 \%$ of participants completing the program, respectively.

\section{Attendance}

Looking at the rate of attendance, significant differences were noted in comparing five different LUNCH Groups ${ }^{\oplus}$ programs, $F_{(4,166)}=8.155, p<.001$. Using the Tukey method for posthoc comparisons, those in the online version of the 2019-2020 LUNCH Groups ${ }^{\oplus}$ School Year Program $(M=.887)$ and those in the Online 2020-2021 LUNCH Groups ${ }^{\circledR}$ School Year Program ( $M=$.944) had significantly higher rates of attendance relative to those in the traditional, in-person version of the 2019-2020 LUNCH Groups ${ }^{\circledR}$ School Year Program $(M=.764)$, with $95 \%$ Cls of $[.022, .222]$ and $[.069, .290]$, respectively. Rates of attendance did not significantly differ between the two online versions of the School Year program, 95\% Cl=[-.060, .175], $p>.05$. Similarly, rates of attendance did not significantly differ between the in-person and online versions of the Summer Programs, 95\% Cl $=[-.104, .128], p>.05$.

Before the pandemic, attrition and attendance rates reflected common logistical limitations of traditional psychological services, including travel and scheduling-related challenges, particularly during the school year. Problems have arisen given that students are spending their full day in class and then require the caregiver or other supportive adult involvement to commute to our program. Observed differences in rates of attrition and attendance across timepoints may suggest that online-based services lower the barriers to attendance. The slight drop off in the number of students enrolled in the program following the transition to online services may be linked to the stress of adjusting to "pandemic life," technology fatigue, lack of familiarity and understanding associated with telehealth services, or program changes that no longer appeared aligned with the family's goals for treatment. However, when caregivers and their children were aware of and had committed to telehealth treatment, they may have been able to adapt implicitly held expectations for the family and therapist roles, the therapeutic process and environment, and outcomes. In particular, when expectations for online services were made clear at intake, rates of engagement and attrition appeared similar across programs.

\section{Results}

\section{Feedback from the Students and Families}

Due to the clinical nature of the $\mathrm{LUNCH}_{\text {Groups }}{ }^{\circledR}$ program in unity with the unanticipated transition to online services, data collection was not systematic across programs; however, direct feedback was elicited from students and families at various points in order to inform the development of ongoing online programs. Data from 23 children enrolled in the Summer 2020 online Program indicated that $83 \%$ of students would recommend that "other children come to a group like this," $4 \%$ of students indicated that they would "maybe" recommend the program, and $13 \%$ indicated that they would not recommend the program. This is consistent with parent feedback for this same period indicating that $96 \%$ of parents would recommend the program to other families. It is also consistent with prior parent-report data indicating that $85 \%-95 \%$ of students reported enjoying the program, $65 \%-74 \%$ made significant gains, and $40 \%$ of students showed evidence of generalization (Gale 2012).

More extensive feedback was gathered from the families who completed the interim survey half-way through the School Year 2020-2021 program (a total of 26 families participated in the school year program). A total of 26 families participated in the school year program. Data were excluded for four families that had only recently joined the program. With a sample of 22 students, $77 \%$ of parents reported that the program structure and curriculum appeared to meet their child's needs, while 18\% reported "No Opinion" and the remaining 5\% disagreed. Regarding positive behavioral changes associated with the program, 


\section{iejee $\approx$}

$68 \%$ of families reported observing at least one major change in their child (would have been 64\% with $N=26$ ), and $82 \%$ of families reported observing minor changes. Overall, $64 \%$ of families rated the program positively; $28 \%$ of families rated the program as "excellent"; 36\% rated it as "very good"; $32 \%$ of families rated the program as "good"; and $4 \%$ rated it as "fair." Parents cited their children's global overuse of virtual communication following the pandemic as the most common reason major behavioral changes might not have been observed.

Sample qualitative feedback received from parents ( $N=22$ ) regarding behavioral changes and outcomes observed in relation to participation in the School Year 2020-2021 program included:

- "His class interactions have improved, especially in breakout sessions with the other kids. He really struggled at the beginning of the school year and was typing things in chat and being disruptive. I think having the LUNCH Group ${ }^{\oplus}$ be in a similar format to school has helped."

- "Improved regulation when faced with unwanted demands."

- "More respectful"

- "More organized...keeping up with the schedule without or very little prompts."

- "He is learning to control his emotions better. When things don't go his way he always puts his face in his hands. I noticed he does less of this and he seems to be happier in life."

- "He became more patient than before."

- "Not sure. It sounds like she wasn'† exhibiting behaviors early on"

- "I have noticed no changes."

- "Increased ability to sit, pay attention and follow instructions."

- "Engaging in more socially appropriate ways online."

- "He is starting to acknowledge when you ask something."

- "[Student] has shown better affect regulation in the past 6 months."

- "More flexibility "

- "Frustration tolerance improved"

- "More control over his urge to play with the mouse and keyboard even though not a completely resolved problem"

In general, rates of reported behavioral change fell slightly below those obtained from parents participating in prior in-person programs which averaged $74 \%$ observed major gains for the period 2008 to 2017 (Gale, 2018). Conversely, these rates suggest improvement from the online 2020 Summer program (Gale, 2020). The most common comment raised by parents in the 2020 Summer Program was that the limited duration of the overall program (six sessions) was not enough to identify and work on behavior change. The online 2020-2021 School Year program addressed this feedback by reinstating the treatment duration to October through May while limiting the weekly session length to 60 or 75 minutes of the group per week to reduce fatigue. The present results suggest that $92 \%$ of families are comfortable with the frequency of online meetings while $8 \%$ would hope for more frequent meetings. Eighty-five percent of families are comfortable with the duration of each meeting, while $8 \%$ perceive the sessions as too long and $8 \%$ perceive the sessions as too short. Concerns related to session frequency and length in the present online program was "NOT the length of the program; it's that everything's online and it's become too much," as one parent enunciated.

Parents with children who had previously participated in one of the traditional, in-person programs $(N=16)$ were specifically asked to highlight perceived benefits and challenges associated with each environment.

- "Nothing compares to the in-person program! However, the goals of social skills and adaptive skills are the same regardless of the platform."

- "Online social skills are new and so difficult."

- "In the in-person meeting, you were able to practice a different lifestyle \& that was a new \& good experience for [Student], like going to different food places \& trying new things."

- During online meetings, [Student] can lose focus easier, he doesn't have the drive to participate in conversation, it is more difficult for him to try to make friends."

- "[Student] really misses the in-person program. I think he really enjoyed being social in-person and going out to dinner."

- "Online feels very controlled and productive. We miss the in-person social interaction that gives better feedback about social skills."

- "Lots of pros. [Student] likes computers so teleHeath has helped him."

- "in-person - super effective for kids and parents alike. Virtual - mostly effective for us parents as an ongoing review of how to better manage with [Student]."

- "Online keeps him calmer, but nothing beats in-person socializing."

- "The only pro of the online program is saving time on travel, but that's negligible. Otherwise, can't wait for the program to be back to inperson mode."

- "Less personal time for kids to chat with other kids." 
Themes emerged within the feedback offered by parents, identifying both strengths and drawbacks associated with the implementation of an online model for social skills groups. Reported benefits of the online program have included more personalized interactions with peers and staff, more practice with reading peers' facial expressions, increased opportunities for students to practice self-management and selfregulation, as well as increased engagement among students with interest in computers and technology. Feasibility and acceptability were also highlighted as key benefits of the online model. In particular, the reduced commute appeared to increase access to group activities and parent meetings. Challenges associated with the online program have included limited naturalistic interactions among the students/ increased staff guidance in the group environment, reduced opportunities to practice community-based activities (e.g., going out to dinner), and increased difficulty maintaining focus.

The research suggests that the present online model of the online LUNCH Groups ${ }^{\circledR}$ program may hold clinical utility and be an effective support for children with transdiagnostic challenges, particularly when online services serve as an adjunct to in-person engagement. However, the pandemic and lockdown circumstances surrounding the implementation of a purely online model may be interfering with the potential for, and generalization of, gains. This may indicate that the online model of the LUNCH Groups ${ }^{\circledR}$ program may serve as a beneficial tool for supporting students overall and may be perceived more positively when integrated as an adjunct to in-person engagement. The biggest limitation is that generalization is presently limited to face-to-face family interactions and telesocializing due to social distancing. We know that practice with peers is an essential part of the process. Once this element has returned, it will be interesting to see how online treatment compares to in-person.

\section{Discussion and Conclusions}

The utility of in-person social skills programs has been firmly established through a variety of intervention models. The sudden emergence of a world-wide pandemic has sharpened the need to confirm the efficacy of online variants. While in-person service may provide a superior treatment experience for some students, online treatment benefits have emerged as well. For some families, the barriers to treatment involving transportation and other logistics may result in no treatment, inconsistent treatment, or premature termination. For these families, telehealth delivery for group treatment may be their best option.

Some of the challenges associated with the development of telehealth-based social skills groups include the development of a curriculum that is both meaningful and sufficiently engaging for students. One of our greatest challenges has been with middle school students who appear to be playing games, watching videos, or otherwise engaged in distracting activities during group. A few interventions are currently being piloted to address this concern. Fortunately, looking at the program as a whole, this has been a problem for only about $15 \%$ of our participants. Finding a suitable spot to participate in the group that provides comfortable seating and little environmental interference has also been a challenge to the online delivery model. During session, environmental interference has included parents walking in the background, on their own phone calls, unaware that the group is hearing everything they can say.

After treating about 70 students for nearly a year across three different program delivery models (in person, virtual limited-treatment summer session, and virtual school year session), fortunately, there have been no significant crises and the emergency procedures of contacting the parent by phone or email when a serious concern has arisen have worked out as expected. However, a HIPAA violation nightmare was narrowly averted when a parent snapped a photo of her daughter during a session and planned to post it online. Apprising families of the limitations and potential risks of online treatment and maintaining a vigilant approach is essential.

Learning to reformulate the pace of treatment services in the area of parent education has been an important element. Wearing so many hats right now, parent, teacher, hall monitor, technology support, and playmate, parents are understandably stretched thin. Accordingly, while collecting data, being consistent in their approach to their child, and managing stress are all viable parent goals, although, those goals may seem a bit lofty at present. Understanding each family's situations and resources can lead to more tailoring parent group support. Our researchers are currently piloting such a system using two programs, Knowmia and Teachable, to provide more individualized support. As neither of these solutions is out-of-the-box HIPAA compliant, we are looking at a workaround.

It is extremely important to be familiar with the technology used for telehealth. To that end, videos have been created to help families understand how bandwidth works and what to do if they have an unstable connection. As a provider, whenever possible, a wired connection has proven to be most effective (50 feet network cables come in quite handy).

Our researchers have not normally collected data mid-program, but that turned out to be extremely useful this year, and we will plan to continue this 


\section{iejee $\approx$}

moving forward. We have modified our survey data to reflect the differences between in-person and online better. Eventually, we will likely need to modify it again when moving to a hybrid model. The greatest challenge to the LUNCH Groups ${ }^{\circledR}$ program has been collecting sufficient standardized pre-post data to document quantitative outcomes. Our survey tools have been sufficient for writing reports and satisfying funding requests from schools and agencies, but they might not be sufficient for broad scale generalization and evidence of efficacy. Our program would benefit from increased quantitative data to support our observations and conclusions. This quandary highlights one of the major challenges with collecting research data within the confines of clinical programs that are not grant-funded. Collecting additional data would require additional staff, materials, time, and funds. In general, families who participate in clinical programs do not remain enrolled if they do not see a clinical benefit. This is especially true during our eightmonth program.

One parent phrased it nicely, "Being virtual [at this time is a] necessary evil." Many families are holding hope for the return to purely in-person sessions where their children can practice social skills in naturalistic and community settings. However, while options are currently limited due to the pandemic, we have observed and heard that there is both hope and value in the online model of the LUNCH Groups ${ }^{\circledR}$. Another parent noted, "During a very isolated time in our teenage daughter's life, she has a community and sense of belonging and social interaction."

The current situation may not be ideal, but in reviewing parent perceptions of major and minor behavioral change, it appears that an online social skills program holds tremendous potential for benefiting students. Furthermore, our study revealed that parent education and support provided via telehealth, may be equal to, if not superior to in-person parent meetings (especially when all of the logistical elements are considered).

An especially rewarding aspect of the program has been to hear from families who participated in earlier years and to learn how their children have flourished. Working with 1600 families since the inception of LUNCH Groups ${ }^{\circledast}$ has provided a rich clinical database that continues to help us address a wide range of child social behavioral challenges. While there remains room for improvement and further refinement of the online, and anticipated hybrid delivery model, the overwhelmingly positive parent feedback of the online LUNCH Groups ${ }^{\circledR}$ model suggests that the online delivery model holds both clinical and functional utility in supporting the social development of children.

\section{References}

Anthony, C. J., Elliott, S. N., DiPerna, J. C., \& Lei, P.-W. (2020). Multirater assessment of young children's social and emotional learning via the SSIS SEL Brief Scales - Preschool Forms. Early Childhood Research Quarterly, 53, 625-637. https://doi. org/10.1016/j.ecresq.2020.07.006

Bandura, A., Jeffery, R. W., \& Gajdos, E. (1975). Generalizing change through participant modeling with self-directed mastery. Behaviour Research and Therapy, 13(2-3), 141-152. https:// doi.org/10.1016/0005-7967(75)90008-x

Bandura, A. (1977). Self-efficacy: Toward a unifying theory of behavioral change. Psychological Review, 84(2), 191-215. https://doi. org/10.1037/0033-295X.84.2.191

Barlow, D. H., \& Farchione, T. J. (Eds.). (2017). Applications of the unified protocol for transdiagnostic treatment of emotional disorders. Oxford University Press. https://doi.org/10.1093/medpsych/9780190255541.001.0001

Berler, E. S., Gross, A. M., \& Drabman, R. S. (1982). Social skills training with children: Proceed with caution. Journal of Applied Behavior Analysis, 15(1), 41-53). https://doi.org/10.1901/jaba.1982.1541

Chu, B. C., Temkin, A. B., \& Toffey, K. (2016). Transdiagnostic mechanisms and treatment for children and adolescents. Oxford University Press. https://doi. org/10.1093/oxfordhb/9780199935291.013.10

Coles, E. K., Pelham, W. E., Gnagy, E. M., BurrowsMaclean, L., Fabiano, G. A., Chacko, A., Wymbs, B. T., Tresco, K. E., Walker, K. S., \& Robb, J. A. (2005). A Controlled Evaluation of Behavioral Treatment With Children With ADHD Attending a Summer Treatment Program. Journal of Emotional and Behavioral Disorders, 13(2), 99-112. https://doi.or g/10.1177/10634266050130020301

Cui, L., Yufeng, W., \& Xilin, W. (2004). The role of social skills training in treatment of children with behavior problems. Chinese Mental Health Journal, 18(9), 603-606.

Davies, L., LeClair, K. L., Bagley, P., Blunt, H., Hinton, L., Ryan, S., \& Ziebland, S. (2020). Face-to-face compared with online collected accounts of health and illness experiences: A scoping review. Qualitative Health Research, 30(13), 2092-2102. https://doi.org/10.1177/1049732320935835 
Didehbani, N., Allen, T., Kandalaft, M., Krawczyk, D., \& Chapman, S. (2016). Virtual Reality Social Cognition Training for children with high functioning autism. Computers in Human Behavior, 62, 703-711. https://doi.org/10.1016/j. chb.2016.04.033

Fabiano, G. A., Schatz, N. K., \& Pelham, W. E., Jr. (2014). Summer treatment programs for youth with ADHD. Child and Adolescent Psychiatric Clinics of North America, 23(4), 757-773. https://doi. org/10.1016/j.chc.2014.05.012

Fernández-Martínez, I., Orgilés, M., Morales, A., Espada, J. P., \& Essau, C. A. (2020). One-Year followup effects of a cognitive behavior therapybased transdiagnostic program for emotional problems in young children: A school-based cluster-randomized controlled trial. Journal of Affective Disorders, 262, 258-266. https://doi. org/10.1016/j.jad.2019.11.002

Gale, B. (2018, December 5). Methodology and Outcomes for LUNCH Groups ${ }^{\circledR}$, a transdiagnostic time-limited social learning program. Children's Hospital, Los Angeles Grand Rounds.

Gale, B. (2020). Return to Services Survey. [Data set]. BehaviorTech Solutions, Inc. https://sites.google. com/bgalephd.com/rovendorsurveyresults/ introduction?authuser=0

Gale, B. M. (2011). Oppositional Defiant Disorder. In C. Draper \& W. T. O'Donohue (Eds.), Stepped Care and e-Health: Practical Applications to Behavioral Disorders (pp. 181-202). Springer. https://doi.org/10.1007/978-1-4419-6510-3_10

Gale, B. M. (2020). 2020 SUMMER LUNCH GROUPS ${ }^{\circledR}$ [Data Set] BehaviorTech Solutions, Inc.

Gale, B., Mazor, J., \& Harrell, A. (2017). Developing/ Running Transdiagnostic Social Skills Intervention Programs for Children \& Adolescents. The Los Angeles Psychologist, Fall. https://www. researchgate.net/publication/319631508_ DevelopingRunning_Transdiagnostic_Social_ Skills_Intervention_Programs_for_Children_ Adolescents

Gates, J. A., Kang, E., \& Lerner, M. D. (2017). Efficacy of group social skills interventions for youth with autism spectrum disorder: A systematic review and meta-analysis. Clinical Psychology Review, 52, 164-181. https://doi.org/10.1016/j. cpr.2017.01.006
Goldstein, F., \& Glueck, D. (2016). Developing rapport and therapeutic alliance during telemental health sessions with children and adolescents. Journal of Child and Adolescent Psychopharmacology, 26(3), 204-211. https://doi. org/10.1089/cap.2015.0022

Gunderson, E. A., Gripshover, S. J., Romero, C., Dweck, C. S., Goldin-Meadow, S., \& Levine, S. C. (2013). Parent praise to 1- to 3-year-olds predicts children's motivational frameworks 5 years later. Child Development, 84(5), 1526-1541. https://doi. org/10.1111/cdev.12064

Harrell, A., \& Gale, B. (2014). Cross-Validation of an Online Behavior Assessment Tool; Parent Support as a Significant Mediator in Behavioral Intervention. Unpublished data.

Horne, A. M., Nitza, A., Dobias, B. F., Joliff, D. L., Raczynski, K. A., \& Voors, W. (2012). Empower teen peers to prevent bullying: The Bully Busters program for high school. In Empower teen peers to prevent bullying: The Bully Busters program for high school. (pp. xii, $18-x i i, 18)$. Research Press.

Kandalaft, M. R., Didehbani, N., Krawczyk, D. C., Allen, T. T., \& Chapman, S. B. (2013). Virtual reality social cognition training for young adults with high-functioning autism. Journal of Autism and Developmental Disorders, 43(1), 34-44. https:// doi.org/10.1007/s10803-012-1544-6

Laugeson, E. A., Frankel, F., Gantman, A., Dillon, A. R., \& Mogil, C. (2012). Evidence-based social skills training for adolescents with autism spectrum disorders: the UCLA PEERS program. Journal of Autism and Developmental Disorders, 42(6), 1025-1036. https://doi.org/10.1007/s10803-0111339-1

Lavrič, M., \& Naterer, A. (2020). The power of authoritative parenting: A cross-national study of effects of exposure to different parenting styles on life satisfaction. Children and Youth Services Review, 116, 105274. https://doi. org/10.1016/j.childyouth.2020.105274

Mandelberg, J., Laugeson, E. A., Cunningham, T. D., Ellingsen, R., Bates, S., \& Frankel, F. (2014). LongTerm Treatment Outcomes for Parent-Assisted Social Skills Training for Adolescents With Autism Spectrum Disorders: The UCLA PEERS Program. Journal of Mental Health Research in Intellectual Disabilities, 7(1), 45-73. https://doi.org $/ 10.1080 / 19315864.2012 .730600$ 


\section{iejee}

Papazoglou, A., Jacobson, L. A., \& Zabel, T. A. (2013). Sensitivity of the BASC-2 Adaptive Skills Composite in detecting adaptive impairment in a clinically referred sample of children and adolescents. The Clinical Neuropsychologist, 27(3), 386-395. https://doi.org/10.1080/13854046. 2012.760651

Payne, L., Flannery, H., Kambakara Gedara, C., Daniilidi, X., Hitchcock, M., Lambert, D., Taylor, C., \& Christie, D. (2020). Business as usual? Psychological support at a distance. Clinical Child Psychology and Psychiatry, 25(3), 672-686. https://doi.org/10.1177/1359104520937378

Schohl, K. A., Van Hecke, A. V., Carson, A. M., Dolan, B., Karst, J., \& Stevens, S. (2014). A replication and extension of the PEERS intervention: examining effects on social skills and social anxiety in adolescents with autism spectrum disorders. Journal of Autism and Developmental Disorders, 44(3), 532-545. https://doi.org/10.1007/s10803013-1900-1

Soares, E. E., Bausback, K., Beard, C. L., Higinbotham, M., Bunge, E. L., \& Gengoux, G. W. (2021). Social skills training for autism spectrum disorder: A meta-analysis of in-person and technological interventions. Journal of Technology in Behavioral Science, 6, 166-180, https://doi. org/10.1007/s41347-020-00177-0

Spence, S. H. (2003). Social skills training with children and young people: Theory, evidence and practice. Child and Adolescent Mental Health, 8(2), 84-96. https://doi.org/10.1111/14753588.00051

Steinberg, L., Lamborn, S. D., Dornbusch, S. M., \& Darling, N. (1992). Impact of parenting practices on adolescent achievement: authoritative parenting, school involvement, and encouragement to succeed. Child Development, 63(5), 1266-1281. https://doi. org/10.1111/j.1467-8624.1992.tb01694.x

Trip, S., Bora, C., Sipos-Gug, S., Tocai, I., Gradinger, P., Yanagida, T., \& Strohmeier, D. (2015). Bullying prevention in schools by targeting cognitions, emotions, and behavior: Evaluating the effectiveness of the REBE-ViSC program. Journal of Counseling Psychology, 62(4), 732-740. https:// doi.org/10.1037/cou0000084

US Department of Education. (2001). Individuals with Disabilities Education Act (IDEA) 1997. https:// www2.ed.gov/about/offices/list/oii/nonpublic/ idea1.html
Weinberg, H. (2020). Online group psychotherapy: Challenges and possibilities during COVID19-A practice review. Group Dynamics: Theory, Research, and Practice, 24(3), 201-211. https:// doi.org/10.1037/gdn0000140 